\title{
ANALYSIS OF BEHAVIOR IN THE USE OF PLUG-IN HYBRID ELECTRIC VEHICLE AND HYBRID ELECTRIC VEHICLE IN THE TROPICS
}

\author{
Ghany Heryana \\ Research Center for Advanced Vehicles (RCAVe) ${ }^{1}$ \\ ghany@stt-wastukancana.ac.id \\ DA Sumarsono \\ Research Center for Advanced Vehicles (RCAVe) ${ }^{1}$ \\ danardon@eng.ui.ac.id \\ Mohammad Adhitya \\ Research Center for Advanced Vehicles (RCAVe) ${ }^{1}$ \\ madhitya@rocketmail.com \\ Rolan Siregar \\ Research Center for Advanced Vehicles (RCAVe) ${ }^{1}$ \\ rolansiregar@ft.unsada.ac.id \\ Nazaruddin \\ Research Center for Advanced Vehicles (RCAVe) ${ }^{1}$ \\ nazaruddin@eng.unri.ac.id \\ Fuad Zainuri \\ Research Center for Advanced Vehicles (RCAVe) ${ }^{1}$ \\ fuad.zainuri@mesin.pnj.ac.id \\ Sonki Prasetya \\ Research Center for Advanced Vehicles $(R C A V e)^{1}$ \\ sonki.prasetya@mesin.pnj.ac.id \\ ${ }^{1}$ Faculty of Engineering Universitas Indonesia Depok \\ West Java, Indonesia, 16424
}

\begin{abstract}
This research aims to determine the pattern of Plug-In Hybrid Electric Vehicle (PHEV) usage and fuel consumption for the Jakarta metropolitan area, which includes the cities of Depok, Bogor, Tangerang, Bekasi, and Jakarta itself. Tests were carried out for approximately three months, with regular use. Other types of vehicles for comparison are the Internal Combustion Engine (ICE) and Hybrid Electric Vehicle (HEV) units. Fuel consumption data and vehicle usage patterns are acquired from data loggers. Economic studies are carried out in a simulation that involves the price of a vehicle, a battery, maintenance costs, and fuel prices. The results show that the best PHEV fuel consumption is for the range of $55-80 \mathrm{~km}$, which is $35-40 \mathrm{~km} /$ liter. When compared with HEV, PHEV fuel consumption is $30 \%$ more efficient. HEV's best fuel consumption is $22 \mathrm{~km} /$ liter. The ICE is far behind with $11 \mathrm{~km} / \mathrm{liter}$. However, looking at the economic side, it can be concluded that the price of PHEV is still challenging to reach for the middle class. PHEV is still classified as a luxury car for Indonesia. Assuming the amount of fuel is IDR 9,850/liter, and the vehicle service life is set at ten years, the energy cost for PHEV is around IDR 4,400-IDR 6,000/km. It is higher compare with the energy cost for a conventional car that is around IDR 3,400-IDR 3,900/km. PHEV buyers must receive incentive support from the government, not only at the time of purchase (zero tax) but also for maintenance costs and battery replacement. Indonesia has long experience in manufacturing ICE vehicles. Opening an electric vehicle industry is a strategic solution to reduce the price of these vehicles. The import tax for vehicles in Indonesia is quite high.
\end{abstract}

Keywords: Electric Vehicle, PHEV, Plug-In Hybrid Electric Vehicle, Power Consumption, Hybrid Electric Vehicle, HEV, Internal Combustion Engine.

DOI: $10.21303 / 2461-4262.2021 .001617$ 


\section{Introduction}

Research on the close relationship between economic growth and increased air pollution has been carried out for China and South Korea, and in general, the results are directly proportional [1]. The results of this research must be noted for other cities in the world. It can't be avoided except with a policy of reducing or prohibiting the use of ICE vehicles.

As the epicenter of an economy, Jakarta has become overcrowded by vehicle traffic activities. Congestion always occurs almost every hour of the workday, even on weekends. The number of ICE of more than 4 million certainly causes significant air pollution.

The PHEV success is if the population of its use continues to increase and is proven to reduce air pollution significantly [2]. In a specific range, if the SOC is $100 \%$, the BEV feature can be used in the city when going to the office until returning home [3]. A review of how big the ideal battery size for PHEV in Beijing had been carried out. In that study, the results showed that the PHEV battery suitable for use in the city of Beijing was $6-8 \mathrm{kWh}$ [4], as well as in the United States and the European Union [5]. Similar research that aims to improve the performance of BEV on PHEV was to set the pattern on/off battery charging. As a result, the use of fuel was more efficient, around $17.3 \%$ compared to the existing algorithm [6]. Other studies were strategies for optimizing energy management showed a significant increase in fuel efficiency and a longer battery life [7, 8]. Other efforts from the researchers to extend battery life are also carried out with the Intelligent Double-Layer Control Scheme [9].

Planning a trip route is also not spared into research related to improving PHEV performance. The travel expense estimation model was designed for this [10]. Maintaining the temperature of the battery is also proven to be able to optimize the battery's output power and extend its service life as well. The dynamic program method is used to solve the problem. And the research results showed significant benefits [11]. One crucial parameter that is considered by the buyers is the efficient use of fuel. Of the nine settings, one of the economic considerations of PHEV is fuel consumption to curb weight [12]. Research into the sensitivity of fuel used in conventional vehicles and hybrid vehicles linked to driving behavior was also conducted in the United States [13]. Research on the utility of using PHEV was also carried out in California. The results showed that UF of PHEV for short distances (less than 20 miles or $32 \mathrm{~km}$ ) is very low [14].

The relevance of this research is to provide an overview and data on the development direction of electric vehicles in tropical countries, especially Indonesia. Until now, the manufacture of electric vehicles is still quite expensive. This is not only because the population of electric vehicles is still small, but also because of the addition of a battery which is still one of the most expensive parts of electric vehicles.

The transition from hybrid vehicles to fully electric vehicles will be crucial. Thus, data on the behavior of using electric vehicles is needed so that the determination of the capacity of the components will not be over or under. The hope is that the vehicle will still have good quality but at an affordable price for the middle class.

The more specific research objectives of this research are to determine the behavior and the average distance traveled by the vehicle during use in the weekday. This data will be developed to become a reference called the «drive cycle». Drive cycle is needed as the main data in the design simulation of vehicle power and torque capacity, in this case electric vehicles. This data is also needed to determine where the charging station should be built and what is its power capacity.

\section{PHEV Technology}

In designing a vehicle, considerations related to the maximum speed, acceleration, vehicle weight, load weight, aerodynamic drag, rolling resistance, and incline angle. Vehicle Longitudinal Dynamic Model can be solved by several equations; one of them is below eq. (1) [10, 15]:

$$
P_{r e q}(t)=\left(m \cdot a+\frac{1}{2} \cdot \rho \cdot C_{D} \cdot A \cdot v(t)^{2}+m \cdot g \cdot \sin \alpha+f_{r l} \cdot m \cdot g\right) \cdot v(t),
$$

where $P_{\text {req }}=$ power requirement; $A=$ Frontal area; $m=$ mass; $v=$ velocity; $a=$ acceleration; $g=$ gravity; $\rho=$ density of fluid (air); $\alpha=$ elevation angle; $C_{D}=$ Drag coefficient; $f_{r l}=$ rolling resistant. 
For micro conditions that determine actual road conditions, more complex equations are necessary [16].

PHEV consists of 3 types, namely serial, parallel, and serial-parallel. In the parallel PHEV type, ICE and electric motors are mechanically connected to the gearbox. The torque can be calculated by eq. (2) [10]:

$$
T_{\text {wheel }}(t)=T_{\text {fuel_path }}(t)+T_{\text {ele_path }}(t) .
$$

The PHEV serial type has only one vehicle driving power source, namely an electric motor as the main drive. The torque can be calculated by eq. (3):

$$
T_{\text {wheel }}(t)=T_{\text {ele_path }}(t) \text {, }
$$

where $T_{\text {wheel }}=$ wheel torque; $T_{\text {fuel_path }}=$ torque from ICE; $T_{\text {ele } \_p a t h}=$ torque from electric motor.

The concept of serial/parallel PHEV (Fig. 1) is like a combination of serial types and parallel types. ICE and electric motors have a mechanical connection to the gearbox. ICE is also connected in such a way to the generator as a battery charger. ICE and electric motors can distribute mechanical power independently or in conjunction. The Prius PHEV is a vehicle that has successfully implemented a serial/parallel hybrid quite well.

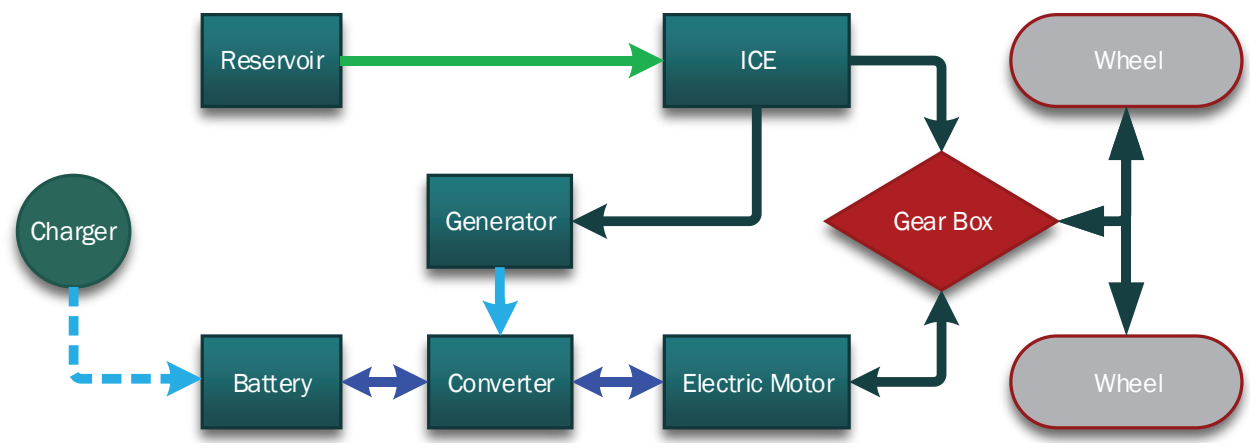

Fig. 1. Serial/Parallel Plug-In Hybrid Electric Vehicle

The total power requirements can be calculated by eq. (4):

$$
P_{\text {total }}(t)=P_{P M}(t)+P_{E P S}(t)+P_{A C}(t)+P_{P W}(t)+P_{\text {zoipers }}(t)+P_{\text {accesories }}(t),
$$

where $P_{\text {total }}=$ total power requirement; $P_{P W}=$ power window power; $P_{P M}=$ prime motor power; $P_{\text {wipers }}=$ wipers power; $P_{E P S}=$ electric power steering power; $P_{\text {accessories }}=$ accessories power; $P_{A C}=$ air conditioner power.

$$
E_{\text {battery }}=V_{\text {battery }} \cdot I h_{\text {battery }},
$$

where $E_{\text {battery }}=$ power of battery; $V_{\text {battery }}=$ voltage of battery; $I h_{\text {batery }}=$ battery current capacity.

Battery energy capacity is the multiplication of voltage $(V)$ with the current hour (Ih) (eq. (5))

\section{Methods}

This study involved six vehicles and six drivers with different driving behavior. The testing is carried out for three months. Similar research has been carried out in the North American area [17], but with a particular PHEV unit. On paper, in theory, PHEV will undoubtedly excel in terms of fuel efficiency, but how much superior is something else that must be tested quantitatively.

Each driver was asked to use the vehicle regularly daily, that is, from the place of residence to the office and back home. It is coupled with other goals that become his/her behavior. The testing 
time is approximately three months. Especially for PHEV, there are additional regulations, namely charging at the office up to $100 \%$ SOC. The charging mode is not explicitly set. A Standard or fast charging mode could be used. Other behaviors return to the driving style of each volunteer. The fuel used is determined using RON92.

The data is processed to determine the pattern of vehicle usage in Jakarta, fuel consumption, and overall efficiency.

\section{Results and Discussion}

\section{1. PHEV Fuel Economy and Driving Distance}

Fig. 2 shows the efficiency of using PHEV fuel with regular use in the Jakarta area and its satellite cities. It appears that the highest efficiency of fuel use was in the range of $50-60 \mathrm{~km}$. The efficiency continued to decline at a distance of more than $60 \mathrm{~km}$. After that, the PHEV will operate as HEV. The best efficiency can reach more than $70 \mathrm{~km} /$ liter. The level of SOC is very influential in this result.

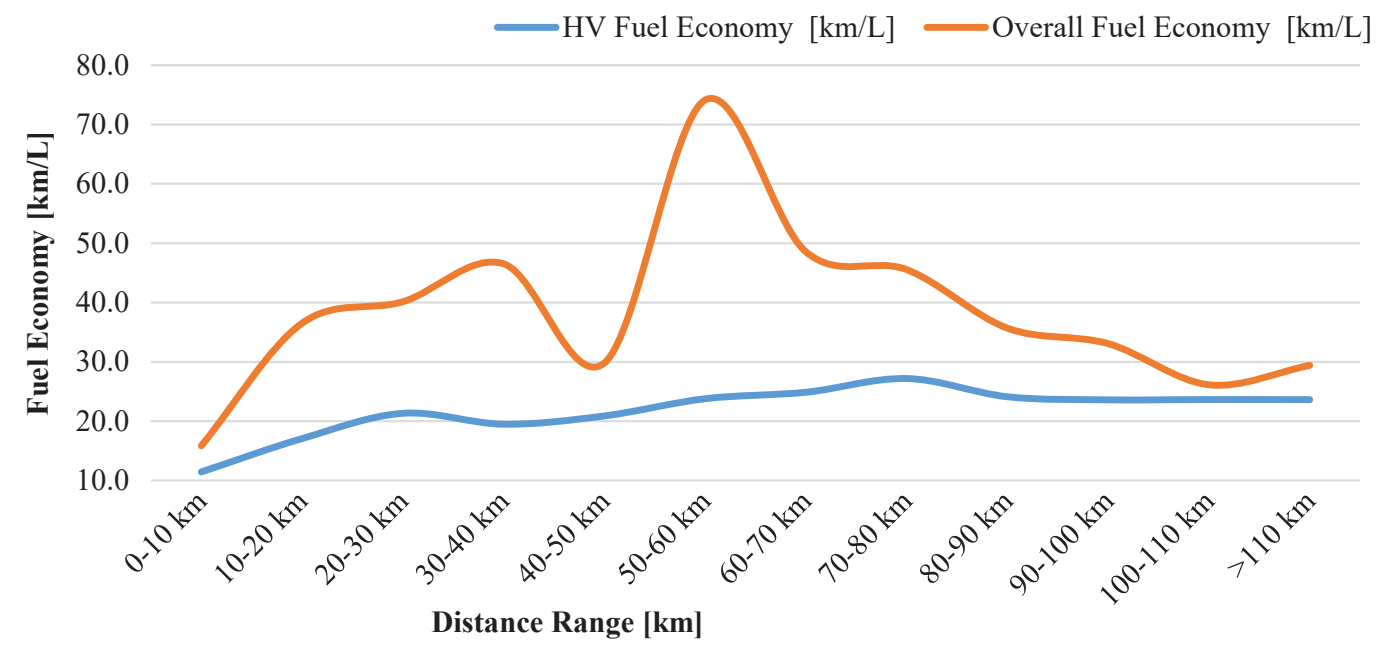

Fig. 2. Fuel Efficiency of PHEV base on the distance range

From Fig. 3, it can be seen that in the range of 30-40 km and 50-60 km, the use of electrical energy was higher than the fuel consumption. If the mileage were more than $60 \mathrm{~km}$, the HV feature would tend to be dominant. Still in the graph $[b]$, after a distance of more than $50 \mathrm{~km}$, the battery capacity for the BEV mode had run out.

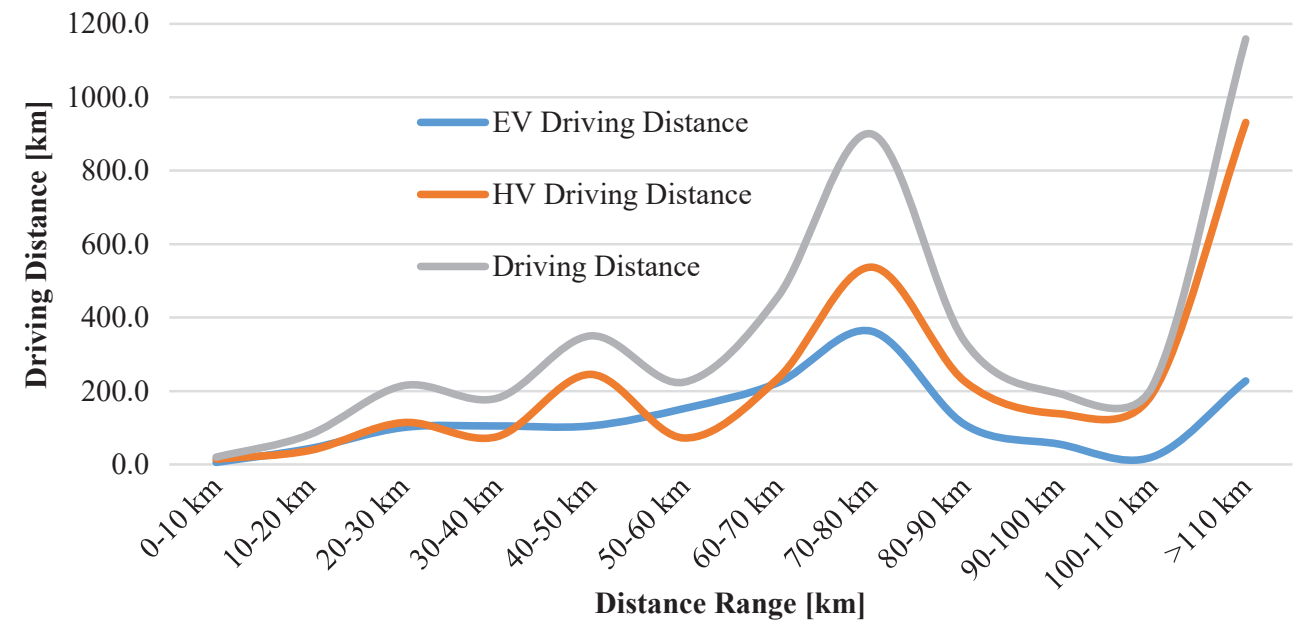

Fig. 3. The tendency of PHEV uses base on the distance range 
In PHEV, the efficiency of fuel use can be increased or dropped dramatically. It is influenced by the frequency of the plug-in charging and the SOC level. It is a sampling form 1 of 2 PHEV units used as test vehicles.

\section{2. PHEV Energy and Power Consumption for Air Conditioner}

Fig. 4 is the result of testing AC power consumption over a set period.

Fig. 5 shows the AC capacity needed at certain hours. Thus, for areas such as Jakarta, for sedan vehicles, cabin AC capacity is required around $1 \mathrm{~kW}$.

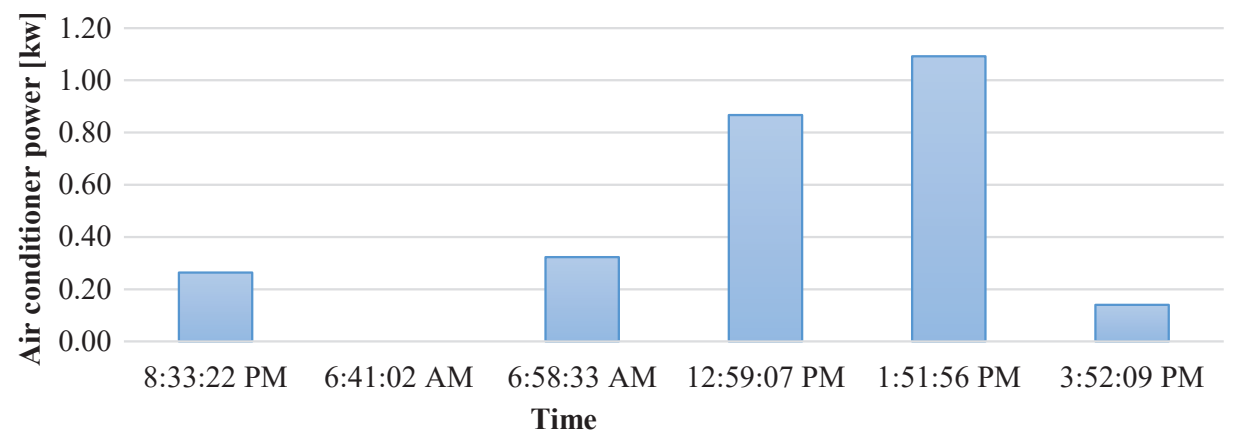

Fig. 4. Electric Vehicle vs. Air Conditioner Energy Consumption in PHEV

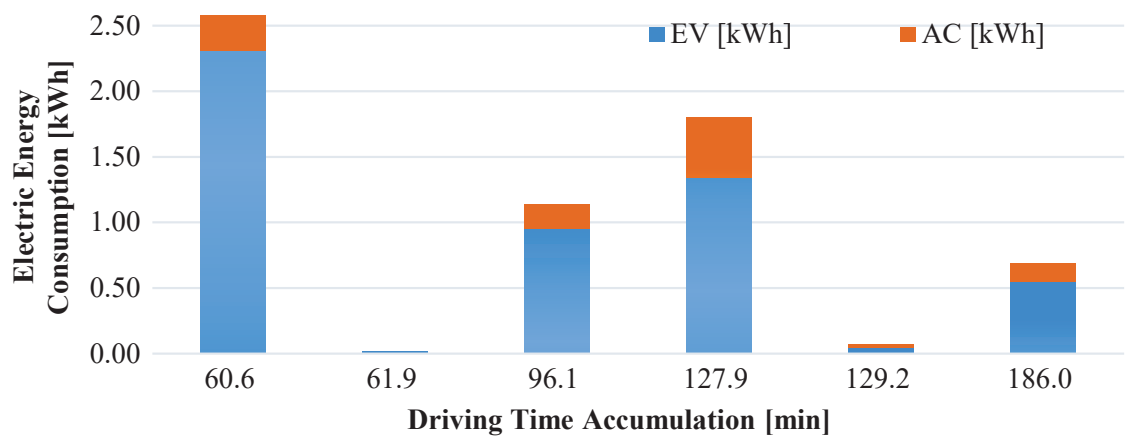

Fig. 5. Air Conditioner Power Consumption of PHEV base on what time it uses

\section{3. Resume Behavior Driving Data}

HEV has better fuel efficiency compared to ICE. Its consumption is in the range of $20 \mathrm{~km} /$ liter (Fig. 6). There is no surge in fuel efficiency at HEV. It is because the battery capacity is limited, and there is no other source of charge for the battery apart from the energy available in the vehicle itself.

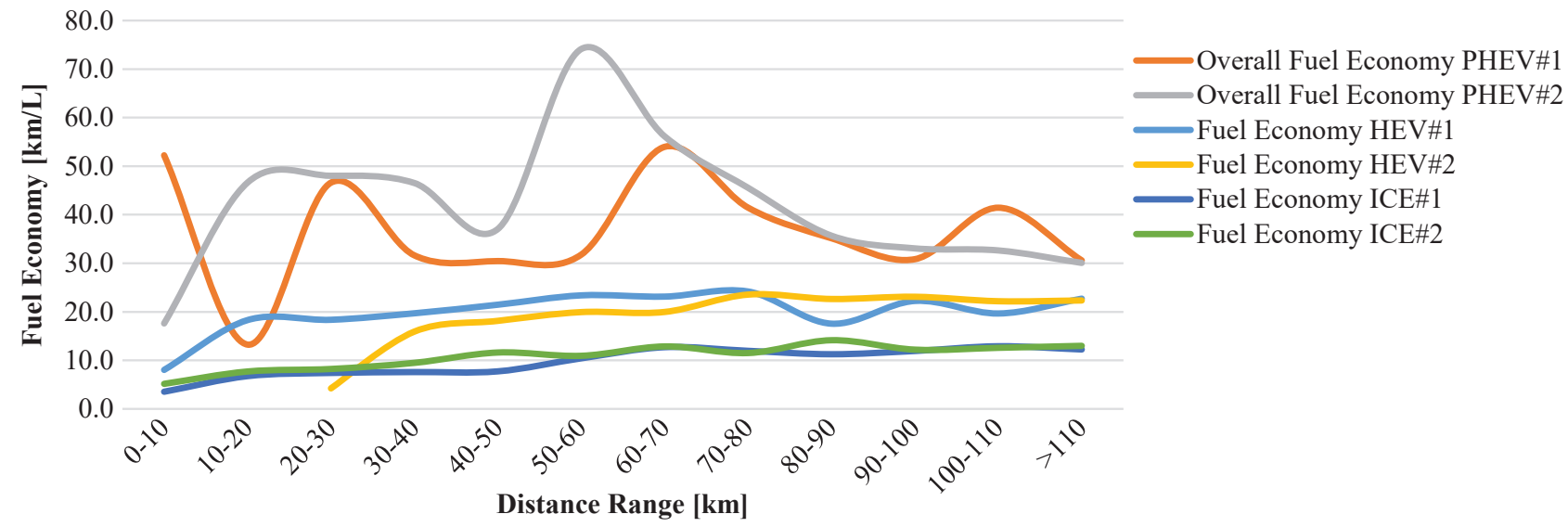

Fig. 6. Fuel Eff. comparison among PHEV, HEV, and ICE 
The surge in fuel economy in the PHEV group shows that efficiency can still be increased continuously by improving driving behavior.

Fig. 7 provides an overview of driving behavior based on distance traveled. It appears that the driver range is dominant at $50-80 \mathrm{~km}$. A distance of more than $100 \mathrm{~km}$ is if the driver travels out of town.

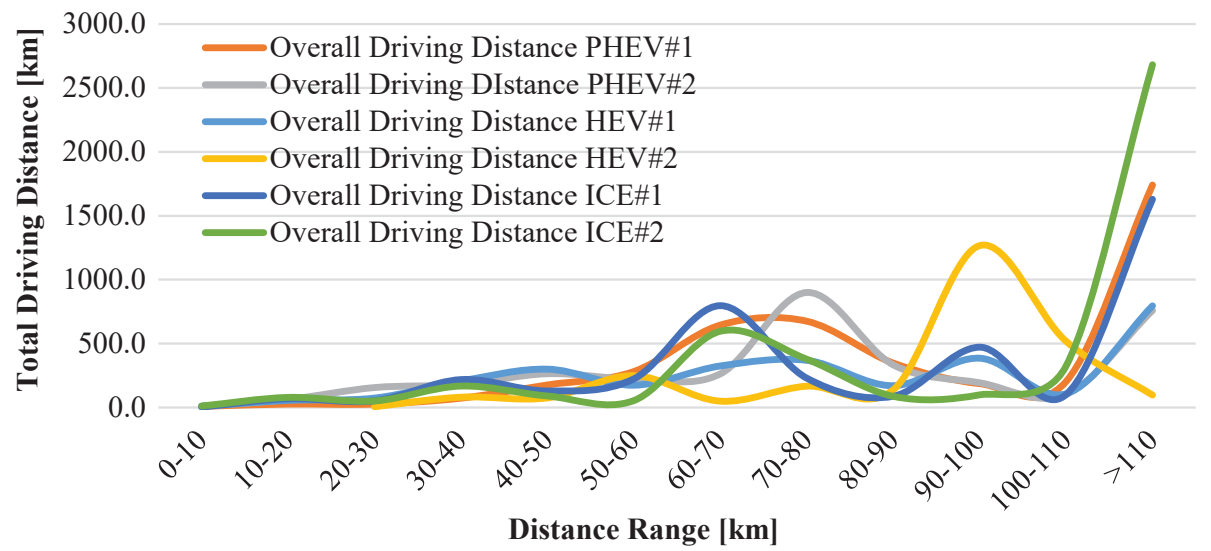

Fig. 7. Total Driving Distance comparison among PHEV, HEV, and ICE

Quantitative data can be found in the table below. From here it can be observed and analyzed in more detail for each vehicle. Both PHEVs consume far less fuel in all (Table 1).

Table 1

Resume of vehicle fuel consumption on regular using in Jakarta

\begin{tabular}{lcccccc}
\hline \multicolumn{1}{c}{ Car Code } & PHEV \#1 & PHEV \#2 & HEV \#1 & HEV \#2 & ICE \#1 & ICE \#2 \\
\hline Number of days [day] & 55 & 62 & 49 & 61 & 58 & 57 \\
Driving time [minute] & 10.904 & 9.373 & 8.153 & 11.965 & 11.226 & 11.807 \\
Number of Charge [times] & 51 & 32 & N/A & N/A & N/A & N/A \\
Average Number of Charge [day/charge] & 1.08 & 1.94 & N/A & N/A & N/A & N/A \\
Average mileage [km/day] & 79.89 & 55.66 & 60.74 & 71.67 & 69.22 & 81.10 \\
Driving Distance [km] & 4.393 & 3.450 & 2.976 & 4.371 & 4.014 & 4.622 \\
Fuel Consumption [liter] & 125.79 & 87.25 & 137.25 & 197.30 & 355.64 & 375.05 \\
Average Fuel Economy [km/liter] & 34.93 & 39.55 & 21.69 & 22.16 & 11.29 & 12.32 \\
Average HV Fuel Economy [km/liter] & 23.59 & 24.02 & N/A & N/A & N/A & N/A \\
HV Driving Distance [km] & 2.967 & 2.095 & N/A & N/A & N/A & N/A \\
EV Driving Distance [km] & 1.425 & 1.354 & N/A & N/A & N/A
\end{tabular}

ICE drains almost three times that of PHEV. Regulations in Indonesia consider the amount of tax based on fuel consumption $/ \mathrm{km}$. Temporary conclusion, PHEV has an excellent opportunity to get tax incentives because of its fuel consumption.

\section{5. Feasibility of PHEV}

Charging time required for Prius PHEV up to $100 \%$ SOC is 3 hours, with $2.3 \mathrm{~kW}$ of power. So the energy should be $6.9 \mathrm{kWh}$ (Table 2). In Indonesia, for that power, the home electricity 
should be at 3500-5500 kVA class. It is the upper middle segment. The energy cost for that segment is IDR $1467.28 / \mathrm{kWh}$.

Table 2

Power requirement and unit cost for energy

\begin{tabular}{lcc}
\hline \multicolumn{1}{c}{ Charging Data } & Value & Remark \\
\hline Charging time (hour) & 3 & {$[18]$} \\
Charging power (kW) & 2.3 & {$[18]$} \\
Charging energy (kWh) & 6.9 & - \\
Energy Cost & - & - \\
Charging cost (IDR/kWh) & 1467.28 & {$[19]$} \\
Gasoline Price (IDR/liter) (RON 92) & 9850 & {$[20]$}
\end{tabular}

Base on Table 2, the ideal house to be fitted with a $2.3 \mathrm{~kW}$ capacity charger is one that has a minimum of $15 \mathrm{~A}$ or 3300 watts of electric power.

\section{Discussion of Experimental Results}

The results of this experiment show that there is still a lot of energy wasted from ICE which can be reused. And the combination of ICE with EV is one solution. This research is sufficient to provide a big picture that there will be fuel savings with the combination of these engines.

In addition, the data show that from the experimental results, the average distance traveled per day is around $50-60 \mathrm{~km}$ (Table 1). AC is always on.

Thus the battery capacity is less than or more than that will make vehicle performance not optimal. From the distance divided by time, it is known that the vehicle is in the speed range of $15-50 \mathrm{~km} / \mathrm{h}$. This will be the material for determining the motor power which does not need to be too large. The smaller the motor power, the smaller the battery consumption, and the farther the distance that can be achieved. With this drive cycle, acceleration and high speed are not the main things.

For the purposes of driving in the city, electric vehicles are designed to cover a distance of only about $50 \mathrm{~km}$. Longer distances can be accommodated by offering a larger battery capacity. The main driving comfort facilities are air conditioners and entertainment devices. The main motor power of $10 \mathrm{KW}$ is sufficient. Thus the battery capacity does not need to be too large. Component prices could be reduced if they could be manufactured in Indonesia. This is to reduce import taxes and to increase local and domestic content. For the quality of vehicle manufacturing, Indonesia has proven to have quite a good experience, both in terms of cost, quality and delivery. This has become Indonesia's main strength to produce and develop its own electric vehicles. Reasonable prices for HEV vehicles are affordable for the lower middle class, namely in the LCGC class (low cost green car), under 250 million rupiah.

However, this study still has shortcomings related to the number and types of vehicles sampled. This is because the pollution of electric vehicles in Indonesia is not as high as in developed countries. This study also has not been able to project how fuel efficiency will be if the vehicle has passed its useful life. Then it is necessary to research the waste battery that has been damaged. To find out the life of the battery, a discharge test is necessary.

\section{Conclusions}

Research and development of PHEV are still very strategic for the next decade or more. When the BEV era emerged, PHEV will not just disappear.

The fuel efficiency of PHEV is quite good, but it is still very possible to be improved if battery technology continues to develop until higher battery densities are found. 
Marketing PHEV in a country is ideal when considering the driving behavior of its population. Also, traffic and climate conditions are essential to be taken into account.

To encourage the purchase of PHEV, in addition to determining the right PHEV specifications for Indonesia, also with government policies in reducing PHEV and BEV taxes, as well as providing other incentives.

The construction of PHEV factories in Indonesia can reduce the selling price of vehicles.

To target the lower middle class, the price of vehicles less than 250 million rupiah is expected to make the development of electric vehicles grow rapidly. The electric vehicle feature in Indonesia doesn't need to be too sophisticated. The only standard comfort needed is air conditioner and entertainment equipment. The motor power of about $50 \mathrm{kw}$ can be reduced to just $10 \mathrm{kw}$.

\section{Acknowledgments}

The authors acknowledge the financial support from the KEMENTERIAN RISET DAN TEKNOLOGI/BADAN RISET DAN INOVASI NASIONAL (RISTEKDIKTI) for Penelitian Dasar Unggulan Perguruan Tinggi (PDUPT) Grant through Contract No. NKB-63/UN2.RST/ HKP.05.00/2020 and PUTI UI (Publikasi Terindex Internasional Universitas Indonesia) Contract No. NKB-643/UN2.RST/HKP.05.00/2020.

\section{References}

[1] Jiang, M., Kim, E., Woo, Y. (2020). The Relationship between Economic Growth and Air Pollution - A Regional Comparison between China and South Korea. International Journal of Environmental Research and Public Health, 17 (8), 2761. doi: https:// doi.org/10.3390/ijerph17082761

[2] Frey, H. C., Zheng, X., Hu, J. (2020). Variability in Measured Real-World Operational Energy Use and Emission Rates of a Plug-In Hybrid Electric Vehicle. Energies, 13 (5), 1140. doi: https://oi.org/10.3390/en13051140

[3] Heryana, G., Prasetya, S., Zainuri, F., Adhitya, M., Sumarsono, D. A., Nazaruddin, Siregar, R. (2020). Plug in hybrid electric vehicle power consumption analysis in tropical area. International conference on emerging applications in material science and technology: ICEAMST 2020. doi: https://doi.org/10.1063/5.0003756

[4] Hou, C., Wang, H., Ouyang, M. (2014). Battery Sizing for Plug-in Hybrid Electric Vehicles in Beijing: A TCO Model Based Analysis. Energies, 7 (8), 5374-5399. doi: https://doi.org/10.3390/en7085374

[5] Kamguia Simeu, S., Brokate, J., Stephens, T., Rousseau, A. (2018). Factors Influencing Energy Consumption and Cost-Competiveness of Plug-in Electric Vehicles. World Electric Vehicle Journal, 9 (2), 23. doi: https://doi.org/10.3390/wevj9020023

[6] Lee, S., Choi, J., Jeong, K., Kim, H. (2015). A Study of Fuel Economy Improvement in a Plug-in Hybrid Electric Vehicle using Engine on/off and Battery Charging Power Control Based on Driver Characteristics. Energies, 8 (9), 10106-10126. doi: https://doi.org/10.3390/en80910106

[7] Liu, Y., Li, J., Ye, M., Qin, D., Zhang, Y., Lei, Z. (2017). Optimal Energy Management Strategy for a Plug-in Hybrid Electric Vehicle Based on Road Grade Information. Energies, 10 (4), 412. doi: https://doi.org/10.3390/en10040412

[8] Nazaruddin, N., Zainuri, F., Siregar, R., Heryana, G., Adhitya, M., Sumarsono, D. (2019). Electric power steering: an overview of dynamics equation and how it's developed for large vehicle. IOP Conference Series: Materials Science and Engineering, 673, 012112. doi: https://doi.org/10.1088/1757-899x/673/1/012112

[9] Rahbari, O., Omar, N., Van Mierlo, J., A. Rosen, M., Coosemans, T., Berecibar, M. (2019). Electric Vehicle Battery Lifetime Extension through an Intelligent Double-Layer Control Scheme. Energies, 12 (8), 1525. doi: https://doi.org/10.3390/ en12081525

[10] Zhang, Y., Chu, L., Fu, Z., Xu, N., Guo, C., Li, Y. et. al. (2017). An Economical Route Planning Method for Plug-In Hybrid Electric Vehicle in Real World. Energies, 10 (11), 1775. doi: https://doi.org/10.3390/en10111775

[11] Shojaei, S., McGordon, A., Robinson, S., Marco, J. (2017). Improving the Performance Attributes of Plug-in Hybrid Electric Vehicles in Hot Climates through Key-Off Battery Cooling. Energies, 10 (12), 2058. doi: https://doi.org/10.3390/en10122058

[12] Baodi Zhang, Fuyuan Yang, Lan Teng, Minggao Ouyang, Kunfang Guo, Weifeng Li, Jiuyu Du (2019). Comparative Analysis of Technical Route and Market Development for Light-Duty PHEV in China and the US. Energies, 12 (19), 3753. doi: https:// doi.org/10.3390/en12193753

[13] Thomas, J., Huff, S., West, B., Chambon, P. (2017). Fuel Consumption Sensitivity of Conventional and Hybrid Electric Light-Duty Gasoline Vehicles to Driving Style. SAE International Journal of Fuels and Lubricants, 10 (3). doi: https:// doi.org/10.4271/2017-01-9379 
[14] Srinivasa Raghavan, S., Tal, G. (2019). Influence of User Preferences on the Revealed Utility Factor of Plug-In Hybrid Electric Vehicles. World Electric Vehicle Journal, 11 (1), 6. doi: https://doi.org/10.3390/wevj11010006

[15] Heryana, G., Prasetya, S., Adhitya, M., Sumarsono, D. A. (2018). Power consumption analysis on large-sized electric bus. IOP Conference Series: Earth and Environmental Science, 105, 012041. doi: https://doi.org/10.1088/1755-1315/105/1/012041

[16] Edie, L. C. (1961). Car-Following and Steady-State Theory for Noncongested Traffic. Operations Research, 9 (1), 66-76. doi: https://doi.org/10.1287/opre.9.1.66

[17] Boston, D., Werthman, A. (2016). Plug-in Vehicle Behaviors: An analysis of charging and driving behavior of Ford plug-in electric vehicles in the real world. World Electric Vehicle Journal, 8 (4), 926-935. doi: https://doi.org/10.3390/wevj8040926

[18] Toyota Prius Plug-in Hybrid (Typ 1). Available at: https:/www.mobilityhouse.com/int_en/electric-cars/toyota/toyota-priusplug-in-typl.html\#toyota-prius-hybrid-typel-charging-information

[19] Daftar Tarif Listrik Terbaru 2021 Kementerian ESDM [Harga kWh]. Available at: https://ifepal.co.id/media/daftar-tariflistrik-terbaru/

[20] Harga BBM: Pertalite, Premium, Pertamax, dan Pertamax Turbo. Available at: https://www.otosia.com/berita/harga-pertalitepremium-pertamax-dan-pertamax-turbo-mei-2018-kln.html 